\title{
Os Cinco Sentidos: a Importância da Percepção Corporal na Vida de Insulinodependentes
}

\author{
Ostolin, Thatiane Lopes Valentim Di Paschoale; Cockell, Fernanda Flávia \\ Universidade Federal de São Paulo Campus Baixada Santista - thati.ostolin@gmail.com
}

Introdução: o grupo operativo Doce Saúde, formado em Outubro de 2011 e desenvolvido em parceria universidade e serviço, tem como intuito a promoção da saúde e prevenção de doenças voltadas à comunidade local de insulinodependentes, assim como a abordagem integral dos participantes, a ampliação do que se entende por processo saúdedoença-cuidado e a educação popular em saúde, rompendo com os fazeres e saberes tradicionais do modelo biomédico vigente. Mensalmente, são realizadas atividades com cerca de 40 pessoas/mês, sendo que em dois encontros a proposta foi refletir sobre a importância dos cinco sentidos e sua inter-relação no cotidiano de um portador de diabetes mellitus. Objetivos: As atividades visaram contribuir para a valorização do saber popular e do diálogo, fortalecendo a cada dia o vínculo estabelecido. no caso específico das oficinas sobre os sentidos corporais, observar a discussão e a experimentação pelo grupo das maneiras pelas quais sentem e percebem o mundo e a realidade à sua volta, contribuindo para os cuidados integrais dos usuários, ampliando as noções de autocuidado e a importância de atentar aos sinais tanto físicos quanto emocionais, assim como suas interrelações, provenientes do próprio corpo no dia-a-dia. e proporcionar maior autonomia aos sujeitos na busca por uma melhor qualidade de vida e na procura precoce do serviço de saúde. Métodos: As atividades consistiram na abordagem contextualizada e isolada de cada um dos sentidos, na qual houve a divisão dos participantes em grupos a fim de otimizar a reflexão e o diálogo pertinentes a cada um. Foram utilizados objetos de texturas e formatos variados, temperos variados, estímulos sonoros cotidianos, imagens e frutas, com as quais foi feito o preparo de uma salada de frutas. Além da observação deste elementos, foi atribuída uma memória afetiva e um significado tanto individual quanto coletivo durante a atividade. ao término de cada etapa, foi feita uma roda de conversa para concluir a atividade. Resultados: a contribuição e colaboração entre serviço e universidade tem se mostrado eficaz, sendo observado a cada atividade o aumento à adesão ao Doce Saúde. Inicialmente, os insulinodepentes apenas frequentavam a unidade para retirar o insumo. Atualmente, o grupo tem crescido e as temáticas abordadas têm sido escolhidas de acordo com a demanda obtida no encontro precendente ou solicitada pelo serviço. Conclusão: a iniciativa é relevante para os extensionistas, estagiários e agentes comunitárias, permitindo a participação ativa nas trocas de experiências e na formação do diálogo com a comunidade, proporcionando maior empoderamento dos sujeitos através de vivências, dinâmicas e do uso de ferramentas educativas, assim como promovendo uma maior interação e identificação entre eles enquanto grupo.

Ostolin, Thatiane Lopes Valentim Di Paschoale; Cockell, Fernanda Flávia. Os Cinco Sentidos: a Importância da Percepção Corporal na Vida de Insulinodependentes. In: Anais do Congresso Internacional de Humanidades \& Humanização em Saúde [= Blucher Medical Proceedings, num.2, vol.1]. São Paulo: Editora Blucher, 2014. ISSN 2357-7282

DOI 10.5151/medpro-cihhs-10827 